Moisés Stahl

Departamento de História da Universidade Federal de São Paulo

- UNIFESP, Guarulhos, SP, Brasil moisesstahl@yahoo.com.br

DOI

http://dx.doi.org/10.1590/2236-463320161314
Ana Carolina Vimieiro Gomes. Uma Ciência Moderna e Imperial: a fisiologia brasileira no final do século XIX (1880-1889). Belo Horizonte, MG: Fino Traço; Campina Grande, PB: EDUEPB; Rio de Janeiro: Ed. FIOCRUZ, 2013. $172 \mathrm{p}$.

\section{Um laboratório para o Império}

As décadas de 1870 e 1880 assinalam um momento decisivo no contexto imperial. Momento em que floresceram diversas instituições científicas e chegaram ao Brasil novos homens de ciência - como o cientista francês Louis Couty (1854-1884) - que traziam em suas bagagens novas ideias, um bando delas, que, por sua vez, prismaram as criticas às instituições imperiais, modelando novos projetos de nação e marcando a crise do Império. Era a primavera da ciência e o outono do Império. Nesse cenário, uma nova instituição científica marcaria o início das pesquisas fisiológicas nos Brasil, o Laboratório de Fisiologia Experimental anexo ao Museu Nacional do Rio de Janeiro.

0 jornalista da Gazeta de Noticias (02 de abril de 1880) que cobriu a inauguração do novo laboratório para o Império detalhadamente descreveu os espaços numa narrativa longa e exclamou que aquele momento significava "uma nova época para a ciência no Brasil". Essa nova época materializada no Laboratório de Fisiologia Experimental tem sua história examinada no livro "Uma ciência moderna e imperial: a fisiologia brasileira no final do século XIX (1880-1889)". A autora do trabalho, Ana Carolina Vimieiro Gomes, investigou o processo de constituição de um novo campo de saber no país, a fisiologia experimental, nas décadas de 1870 e 1880. 0 livro resultou de sua tese de doutoramento realizada na Universidade Federal de Minas Gerais (com estágio no Centre de Recherche Médecine, Sciences, Santé et Société, CERMES, França), a qual recebeu o prêmio de melhor tese pela Sociedade Brasileira de História da Ciência em 2012..

No percurso investigativo, Ana Gomes mirou a idealização, instalação, funcionamento, consolidação e declínio do Laboratório de Fisiologia. Seu objetivo era definir o sentido e o significado das práticas ocorridas no interior do Laboratório, bem como compreender o processo de produção e validação dos acontecimentos científicos realizados pelos atores envolvidos no laboratório. Ana Gomes aponta a significativa representatividade do Laboratório de Fisiologia para a ciência brasileira.

Entre os importantes trabalhos que dedicaram atenção à chegada das ideias científicas e à constituição da ciência nacional a partir da década de 1870, o livro de Ana Gomes tem o mérito de abordar esse período de modo pioneiro, ao examinar o papel central que a fisiologia experimental teve para a agenda científica do Império nas décadas de 1870 e 1880. 0 livro destaca a presença de alguns personagens que sobressaíram no ambiente científico do final do século XIX, como o Imperador Pedro II, o cientista francês Louis Couty e os cientistas brasileiros João Baptista de Lacerda e Ladislau Netto. Pelas ações desses homens é possivel apreender uma complexa rede de saberes científicos que se estabeleceu entre Brasil e França. Rede que apoiou e sustentou a iniciação da fisiologia no Brasil. 
No primeiro capítulo ("Um programa de 'ciência para o Brasil': o Laboratório de Physiologia Experimental do Museu Nacional"), Ana Gomes deslinda o processo de criação do Laboratório no cenário em que a ciência era entendida como agente capaz de transformar uma nação pré-civilizada em uma nação civilizada. Era um desejo de época instituir um programa de ciência para o Brasil como asseverou Louis Couty, o diretor do referido Laboratório. Com isso, a autora afirma que "a fisiologia, configurada na Europa durante o século XIX, parece ter consistido em uma disciplina exemplar para o ideal de ciência almejado para o país" (p. 21). Um dos objetivos da nova ciência a ser introduzida era a de aprimorar os produtos brasileiros, atendendo diretamente aos interesses da agricultura. Como observa Ana Gomes, "o trânsito pelas fazendas produtoras dessas culturas agrícolas foi significativo para o delineamento dos temas que foram privilegiados pela fisiologia experimental quando da implantação do Laboratório do Museu" (p. 27).

Naquele momento, a criação dos laboratórios atendia ao fito de consolidar "uma nação como o Brasil que queria se mostrar desenvolvida intelectualmente, moderna e civilizada". Desse modo, "investir em uma forma de institucionalização de uma ciência experimental, como a criação de laboratórios, poderia ser uma boa maneira de angariar prestígio científico internacional para o pais" (p. 22).

Um dos principais temas de pesquisa no Museu Nacional era sobre a ação fisiológica do curare - veneno utilizado pelos índios da América do Sul. Com a chegada de Louis Couty, em 1879, as investigações científicas sobre o curare e outros temas recrudesceram e para suprir as crescentes demandas de pesquisas, Couty e Lacerda formularam um projeto de criação do Laboratório de Fisiologia Experimental. Para avaliar o projeto, o Imperador Pedro II e o Ministro da Agricultura visitaram o Museu Nacional, local de atuação de Couty, Lacerda e Ladislau Netto (diretor geral do Museu Nacional), e emitiram parecer favorável ao projeto. É interessante destacar, com Gomes, que Couty já havia publicado artigo em que defendia a criação de laboratórios para o país. 0 artigo, bem aceito pelos círculos intelectuais da época, pode ser entendido como um projeto de apresentação de Couty. Apresentava uma argumentação favorável ao que viria a ser o Laboratório e defendia o valor da atuação do homem de ciência para a sociedade.

0 laboratório teve um papel importante na experimentação científica do final dos Oitocentos. Gomes observa que a cultura científica brasileira entendia que a prática da ciência em laboratório deveria ser análoga à da Europa, sendo primordiais o local e as instalações do laboratório. (p. 33-34) Para tanto, "os efeitos fisiológicos de plantas como mate, café, mandioca e outras substancias alimentícias e tóxicas são o elã, o fio condutor que fundamentou as justificativas para promover a implantação de uma instituição que pudesse analisá-las a partir de procedimentos considerados científicos" (p. 35).

Um dos pontos da argumentação da autora se ordena a partir da problematização do Laboratório de Fisiologia nas bases propostas por Bruno Latour e Michel Callon, isto é: "podemos pensar o movimento da laboratorização da fisiologia a partir da seguinte afirmação: 'dê-me um laboratório de fisiologia experimental que eu lhe erguerei ao mundo civilizado'" (p. 38). A legitimação da fisiologia experimental deveria estar aliada aos interesses da agricultura nacional. Seria com base na experimentação e aprimoramento dos produtos da nação que a fisiologia se consolidaria. Assim, diferentes interesses civilizatórios e econômicos de parte da sociedade brasileira, ou seja, 
das elites agroexportadoras se alinhavam.

No segundo capítulo ("O Museu, o Imperador e o Fisiologista na circulação nacional e internacional de conhecimentos de fisiologia brasileira"), Louis Couty e Pedro II são entendidos como mediadores culturais de práticas científicas que aguçavam as esperanças com o futuro do país. Além de Couty e do Imperador, o Museu Nacional, com o Laboratório de Fisiologia anexo, se constituiria em lugar privilegiado de troca, "de encontro entre a ciência europeia e a brasileira" (p. 64). A preocupação da autora nesse capítulo é pensar o Museu Nacional como "espaço estratégico para a inserção da fisiologia experimental - uma vez que este já se constituía de um locus privilegiado de institucionalização das ciências naturais no país" (p. 67).

$\mathrm{Na}$ vinda de Couty para o Brasil, o monarca teve papel importante que pode ser apreendido nas trocas de cartas entre ele e cientistas franceses que recomendaram Couty, assim com entre ele e o próprio Couty (p. 76). $\mathrm{Na}$ interpretação que apresenta das correspondências, Ana Gomes dialoga com dois estudiosos de Pedro II, José Murilo de Carvalho e Lilia Schwarcz, para questionar a ideia de mecenato do Imperador, defendida por eles, e enfatizar sua ação de "mediador cultural", noção que a autora toma emprestada de Serge Gruzinski e Louise Tachot. Segundo a autora, Pedro II deveria ser entendido como "um agente intermediador, ou especificamente um articulador, entre os modelos e práticas científicas da fisiologia europeia do século XIX e o ideal de ciência pretendido para o país naquele tempo" (p. 75). A noção de mediador cultural não elimina, porém, o peso institucional do imperador. Pedro II permanece como "agente relevante na afirmação da fisiologia no Brasil em fins do século XIX" (p. 79).

Por sua vez, Couty ilustra a dimensão circulatória que, segundo Gomes, compôs a inserção da fisiologia no Brasil. Dentro desse processo, Couty constitui-se num intermediador fundamental, agente responsável por colocar em prática tal dinâmica circulatória, no que diz respeito ao movimento de vinda e ida de conhecimentos, tendo destaque suas diversas comunicações apresentadas na Academia de Ciências de Paris e outras instituições análogas. Ressalta o capital científico de Couty como fundamental para a inserção da ciência brasileira nas comunidades científicas da França (p. 91). Diante do seu comprometimento na obra do Laboratório, Gomes levanta a hipótese de que junto aos seus esforços houvesse um projeto pessoal de Couty, quem, ao realizar pesquisas no Brasil, objetivaria o aprimoramento de sua carreira e credibilidade científica no exterior (p. 80).

Por fim, no terceiro capítulo ("Entre Sucessos, Controvérsias e Conflitos: o Declínio Do Laboratório De Fisiologia Experimental"), Ana Gomes registra o ponto alto e o declínio do Laboratório de Fisiologia a partir de meados da década de 1880. Para a autora o auge da fisiologia brasileira foi a descoberta do antídoto - o permanganato de potássio - contra o veneno de cobras por João Baptista de Lacerda. Diz a autora que se "por um lado, esse acontecimento constituiu o ponto alto da fisiologia experimental no país, porque finalmente mostrou-se passivel de ser amalgamada às práticas terapêuticas da medicina, por outro, desencadeou uma controvérsia disciplinar [...]", isto é, querelas entre João Baptista de Lacerda e Louis Couty (p. 99). Outras questões e querelas ainda contribuíram para o declínio da fisiologia experimental, entre eles os problemas institucionais envolvendo Couty e Ladislau Netto, bem como a precoce morte de Couty (p. 99). Todavia, Ana Gomes evidencia que essas querelas são apenas a ponta do iceberg de uma grande disputa científica muito mais profunda, "na qual subjaz uma contro- 
vérsia acerca de diferentes regimes de validação de conhecimentos" (p. 116).

Em linhas gerais, Ana Gomes demonstra que existiram amplos movimentos em prol da ciência e o Laboratório de Fisiologia ocupou lugar de coadunar interesses políticos, econômicos, científicos a fim de elevar o país ao patamar civilizacional pretendido na época. Ao mesmo tempo direciona seus argumentos para demonstrar uma tensão entre o projeto de desenvolvimento de uma ciência nacional e os limites de um Estado monárquico e centralizador (p. 79). A vontade modernizadora era suprimida pela lógica estamental e pela estrutura ambivalente da burocracia político-administrativa do governo imperial que se pretendia moderna, mas era ao mesmo tempo centralizadora e conservadora. Para tanto recorre ao argumento de José Murilo de Carvalho referente à "dialética da ambiguidade", para afirmar que os conflitos no contexto de implantação, consolidação e declínio do Laboratório dão a ver uma relação ambivalente entre os anseios de se afirmar a fisiologia experimental no Brasil e a organização política do governo imperial (p. 141). Gomes aponta que o enfraquecimento do governo imperial e o consequente enfraquecimento político do Imperador tornavam frágeis o esteio, os interesses e os acordos que davam ao Laboratório legitimação social, sustentação política e apoio financeiro. Toda essa trama conflituosa e ambivalente, inclusive interesses extracientíficos, fez da fisiologia experimental uma "ciência que podemos caracterizar de moderna e imperial" (p. 142), explicando ao mesmo tempo seu sucesso e fracasso. 